\title{
Electrodeposition of copper: the nucleation mechanisms
}

\author{
Darko Grujicic, Batric Pesic* \\ Department of Materials, Mining and Metallurgical Engineering and Geology, University of Idaho, McClure Hall, Moscow, ID 83844-3024, USA
}

Received 30 November 2001

\begin{abstract}
The nucleation mechanisms of copper during electrodeposition of thin films from sulfate solutions were studied by utilizing the electrochemical techniques (cyclic voltammetry and chronoamperometry) and atomic force microscopy (AFM). Near atomically smooth glassy carbon was used as the deposition substrate (electrode). The copper nucleation mechanisms were examined as a function of solution $\mathrm{pH}$, copper concentration, deposition potential, temperature, and background electrolyte. It was found that with $\mathrm{pH}$ and copper concentration increase, the nuclei size increased, while the nuclei population density decreased. An increase of deposition potential produced smaller nuclei and higher nuclei population density. Temperature affected the morphology of deposited copper. The presence of background electrolyte also influenced the morphology and population density of copper nuclei. The nucleation mechanisms were examined by fitting the experimental data (chronoamperometry) into the Scharifker-Hills nucleation models. It was found that at $\mathrm{pH} 1$, in the absence of background electrolyte, copper nucleation was instantaneous. At $\mathrm{pH}$ 2 and 3, the mechanism was inconclusive. In the presence of background electrolyte, the mechanism at $\mathrm{pH} 1$ and 2 was mixed, while at $\mathrm{pH} 3$, the mechanism was progressive nucleation. (C) 2002 Elsevier Science Ltd. All rights reserved.
\end{abstract}

Keywords: Atomic force microscopy; Copper electrochemistry; Copper nucleation; Cottrell equation; Nucleation models

\section{Introduction}

In the recent years, copper has been replacing aluminum as a metal for interconnects in the electronic industry. Copper thin films are also used in the multilayer sandwiches of GMR hard disk read heads. Among various methods of copper thin film deposition onto substrates, such as PVD, CVD, and sputtering, the electrochemical methods (electroless and electrolytic) have proven to be least expensive, highly productive and readily adoptable [1].

Copper electrodeposition mechanisms have been studied in two chemical systems: the acidic without complexation [1], and the basic, requiring the presence of buffering [2,3] and complexing reagents, such as amines [4-6]. Copper surface morphology was modu-

\footnotetext{
* Corresponding author. Tel.: +1-208-885-6569; fax: +1-208-8852855

E-mail address: pesic@uidaho.edu (B. Pesic).
}

lated by adding chelating [7-9] and brightening reagents [1].

The advent of scanning probe microscopy (SPM), such as atomic force microscopy (AFM), allows in-situ monitoring of the reactions as they occur. The aim of our investigations, therefore, was to re-examine copper electrodeposition mechanisms by utilizing AFM to provide the correlation between the morphological and electrochemical information at the very beginning of copper electroreduction, i.e. the nucleation stage. Electrochemical techniques, such as cyclic voltammetry (cv) and chronoamperometry (ca) were used, and these had a dual role. First, they served as the methods for copper deposition, and second, they were utilized as diagnostic tools for reaction mechanisms determination. Copper electrodeposition was studied in three different chemical systems: (1) pure acidic copper sulfate solutions, (2) copper complexed by ammonia, and (3) solutions in which copper was chelated by EDTA. This paper presents the study in acidic copper sulfate solutions. The studies from other two systems will be published at a later date [6,9]. 


\section{Experimental}

Electrolytes containing $0.01,0.025$ and $0.05 \mathrm{M}$ of $\mathrm{CuSO}_{4}$ were prepared using reagent grade, chloride free, $\mathrm{CuSO}_{4}$. Solution was adjusted to $\mathrm{pH} 1,2$ and 3 by adding diluted reagent grade sulfuric acid. All solutions were prepared using Type I purity water (Barnstead NANOpure II).

Electrochemical setup was a standard three-electrode cell with glassy carbon as a working electrode, coiled copper wire as a counter electrode, and copper-copper sulfate as a reference electrode. The glassy carbon working electrode $\left(0.442 \mathrm{~cm}^{2}\right)$ was a non-porous disk (Sigri) of nearly atomic smoothness upon polishing. The reference electrode, against which all potentials are reported, was a copper wire immersed in copper sulfate solution $\left(E_{\mathrm{h}}{ }^{\circ}=0.300 \mathrm{~V}\right)$. A ceramic fritted junction was used to establish contact between the electrolyte and the reference electrode. Electrochemical experiments were controlled with a potentiostat-galvanostat (PerkinElmer, PAR EG\&G 273A) under a computerized control (PAR-EG\&G, M270 Software). All experiments were performed under constant temperature conditions $\left(T=25^{\circ} \mathrm{C}\right)$. All experiments were performed in the
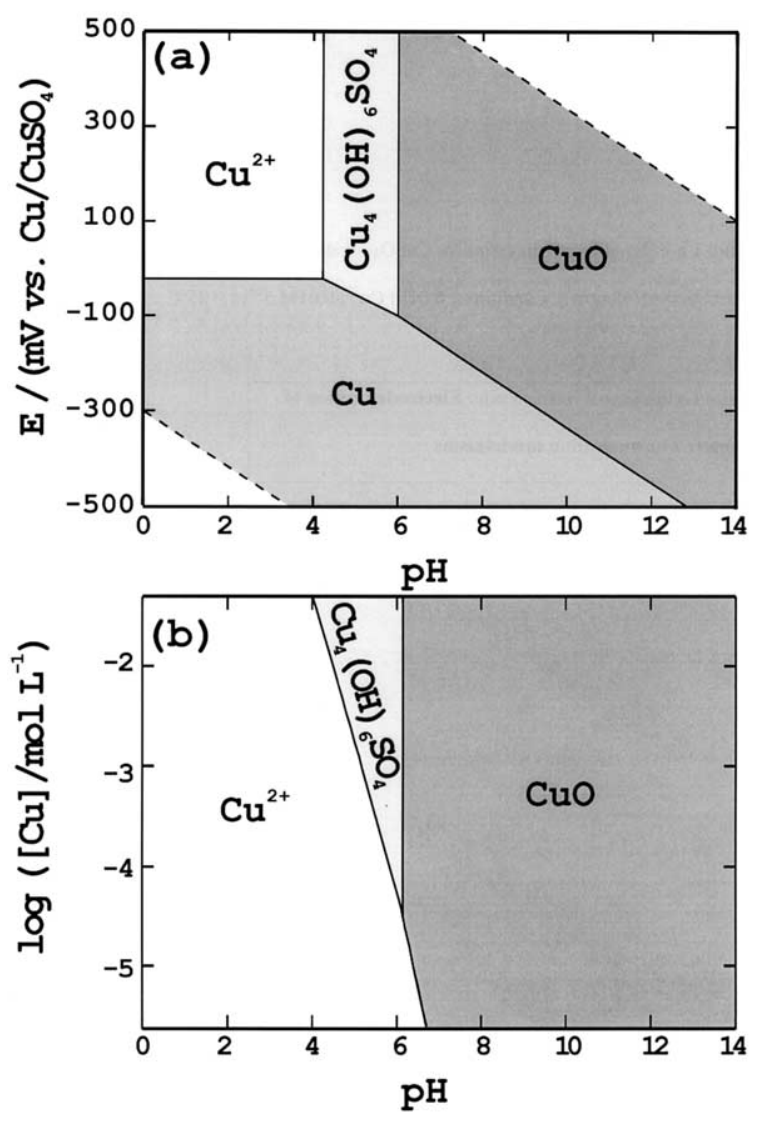

Fig. 1. Equilibrium diagrams for $\mathrm{CuSO}_{4}$-water system: (a) $E_{\mathrm{Cu}^{\prime} \mathrm{Cu}^{2+}}$ $\mathrm{pH}$ diagram, (b) distribution- $\mathrm{pH}$ diagram. Conditions: $0.01 \mathrm{M} \mathrm{Cu}^{2+}$, $0.01 \mathrm{M} \mathrm{S}^{6+}, T=25{ }^{\circ} \mathrm{C}$. absence of background electrolyte except when specified.

Surface morphology was characterized by AFM (VEECO, Digital Instruments, Model Nanoscope IIIa) by using the tapping mode technique under fluid conditions.

Thermodynamic calculations were performed by computerized thermochemical software, STABCAL [10].

\section{Results and discussion}

\subsection{Copper-water chemistry}

Possible species in the copper-water system were first examined by constructing the equilibrium $E_{\mathrm{Cu}^{\prime} \mathrm{Cu}^{2+}}-\mathrm{pH}$ diagram of copper in water, as given in Fig. 1a for $25{ }^{\circ} \mathrm{C}$. According to the $E_{\mathrm{Cu} / \mathrm{Cu}^{2+}}-\mathrm{pH}$ diagram, the cupric ion predominance area is confined to a narrow region between $\mathrm{pH} 0$ and 4.2 and above the solution potential of $-20 \mathrm{mV}$. The solubility-pH diagram, Fig. $1 \mathrm{~b}$, was constructed to determine the equilibrium concentration of cupric ions in the entire $\mathrm{pH}$ range. Accordingly, soluble copper concentration rapidly decreases by two orders of magnitude for a unit increase of $\mathrm{pH}$, yielding to the copper hydroxy sulfate. Consequently, the experiments in this investigation were limited to $\mathrm{pH}$ region in which copper was soluble, i.e. $\mathrm{pH} 1,2$ and 3 .

\subsection{Cyclic voltammetry}

The chemistry of the copper-water system was further studied using cyclic voltammetry. The effect of $\mathrm{pH}$ on cyclic voltammetry of copper $(0.01 \mathrm{M})$ is given in Fig. 2, where $\mathrm{pH} \mathrm{1,2}$ and 3 are represented by solid, dashed and dotted lines, respectively. The cyclic voltammograms corresponding to $\mathrm{pH} 2$ and 3 were compensated for solution resistance. Each cycle commenced at +500 $\mathrm{mV}$, reversed at $-500 \mathrm{mV}$ and terminated at $+500 \mathrm{mV}$. There was no current produced, initially, until potential of $-150 \mathrm{mV}$ was reached. At this voltage, the cathodic current starts to increase and forms the peak Ic at a potential that depends on $\mathrm{pH}$. (1):

$\mathrm{Cu}^{2+}+2 \mathrm{e}=\mathrm{Cu}^{0}$.

The decaying cathodic current past the peak Ic represents the reaction (1) in diffusion controlled regime. Current density at the vertex potential $(-500$ $\mathrm{mV}$ ) was $-1 \mathrm{~mA} \mathrm{~cm}^{-2}$ for $\mathrm{pH} 1$ and 2 and $-2.5 \mathrm{~mA}$ $\mathrm{cm}^{-2}$ for $\mathrm{pH} 3$.

Upon the sweep reversal, the cathodic current density gradually decreases, until it crosses 0 and turns into anodic current. Further sweep in the positive direction 


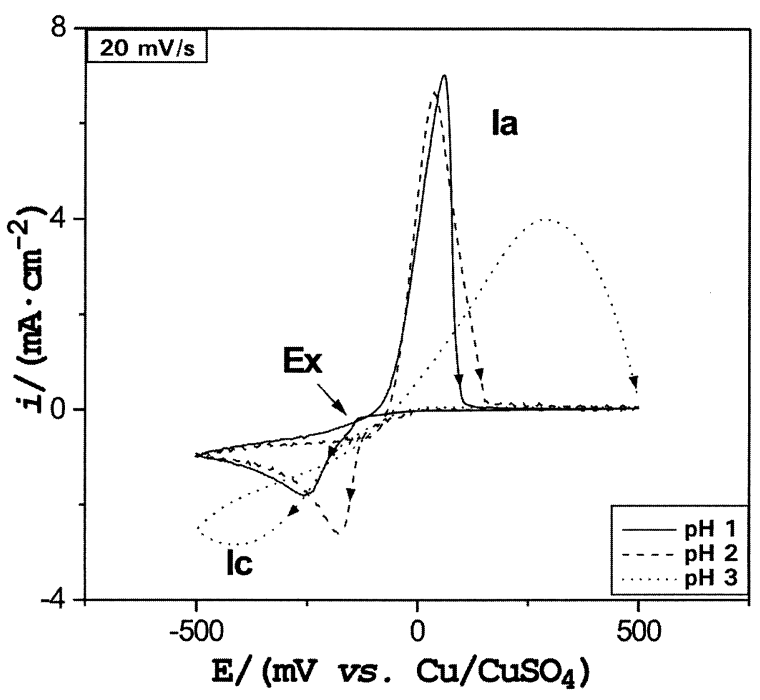

Fig. 2. Cyclic voltammetry of $0.01 \mathrm{M} \mathrm{Cu}^{2+}$ solutions as a function of pH. Ex denotes a crossover potential between cathodic and anodic current traces.

results in the anodic peak Ia, which corresponds to the reaction (1) in the reverse direction. The current density past the peak is 0 , indicating the completion of oxidative dissolution of metallic copper at the electrode surface.

Deposition potential of metallic ions on a foreign substrate is usually higher than deposition potential on the electrode made of the same metal due to crystallographic substrate-metal misfit. Therefore, deposition of copper on glassy carbon commences at potentials that are more negative compared with the redox potential of $\mathrm{Cu} / \mathrm{Cu}^{2+}$. In the anodic direction, however, the oxidation of copper starts from the surface that already has copper deposited, resulting in a potential close to the $\mathrm{Cu} / \mathrm{Cu}^{2+}$ equilibrium potential. Due to the difference in deposition and dissolution potentials, a crossover occurs between the cathodic and anodic current traces [11] at the crossover potential $E_{x}$. The presence of the crossover is diagnostic for the nuclei formation on the electrode. In this study, the crossover occurred for each $\mathrm{pH}$ examined, Fig. 2.

Since reaction (1) is $\mathrm{pH}$ independent, the cyclic voltammograms should also be indistinguishable with respect to this parameter. Nevertheless, half-peak and peak potentials of cyclic voltammograms differ for different $\mathrm{pH}$ values. By examining the resistance of solutions, it was determined that only solutions at $\mathrm{pH} 1$ had negligible resistance. The $0.01 \mathrm{M} \mathrm{Cu}^{2+}$ solution at $\mathrm{pH} 2 \mathrm{had}$ an uncompensated resistance of $104 \Omega$, while the uncompensated resistance of the same solution at pH 3 was $208 \Omega$. Such high uncompensated resistances caused significant IR drops, so that the potential scan was no longer linear [11]. In order to overcome this problem we utilized two different methods for uncompensated resistance elimination.
The first method was instrumental, i.e. the equipment had the capability to determine the IR drop in the electrochemical cell. The solution resistance was subsequently compensated prior to current-voltage curves that were produced, as given in Fig. 2. The IR drop at pH 3 could not be fully eliminated, however.

The second method used $1 \mathrm{M} \mathrm{Na}_{2} \mathrm{SO}_{4}$ as a background electrolyte in order to improve the conductivity of the solution. Addition of sodium sulfate eliminated the uncompensated resistance of the electrolytes at all $\mathrm{pH}$ values. Cyclic voltammograms recorded with the background electrolyte (not presented here) were identical for each solution studied. However, according to the results that will be presented below, sodium sulfate had such profound effects on the nucleation mechanisms of copper that the results obtained with and without the background electrolyte were fundamentally different.

The effect of copper concentration on cyclic voltammetry of copper $(\mathrm{pH} 1)$ is given in Fig. 3, where 0.01, 0.025 and $0.05 \mathrm{M} \mathrm{Cu}^{2+}$, are represented by solid, dashed and dotted lines, respectively. The only effect found was the increase of current density with an increase of copper concentration.

Chronology of events on the surface during an entire cyclic voltammetry scan is presented in Fig. 4. Fig. 4a describes the glassy carbon surface at the beginning and the end of cyclic voltammetry. The AFM image of the glassy carbon surface past the Ic peak, $-300 \mathrm{mV}$, is given in Fig. 4b. Accordingly, the glassy carbon surface is sparsely populated with relatively large $(2.5 \mu \mathrm{m})$ copper nuclei. The next examination of the electrode surface was performed on the sweep reversal at -200 $\mathrm{mV}$, Fig. 4c, immediately prior to the beginning of copper oxidation. The large nuclei formed previously were still present. However, it is also important to note that many new copper nuclei were formed, a phenomenon caused by additional activation of nucleation sites

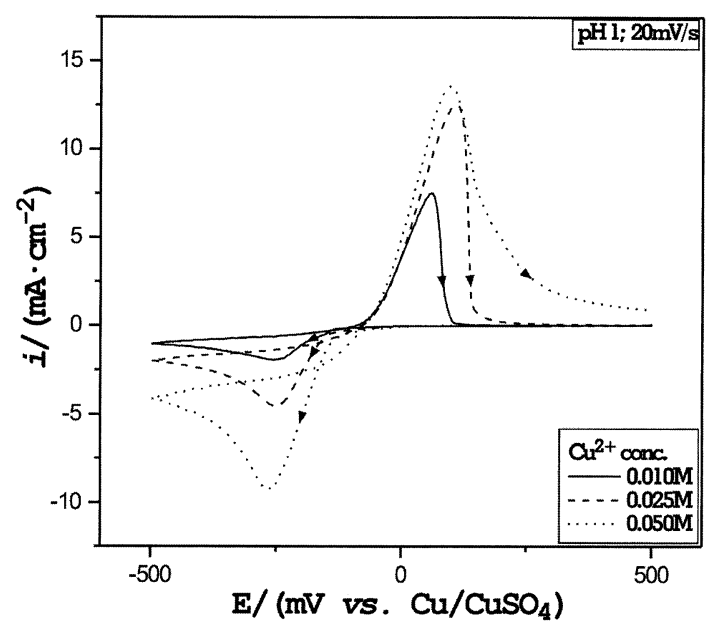

Fig. 3. Effect of copper concentration on cyclic voltammetry of copper at $\mathrm{pH} \mathrm{1,2}$ and 3 . 


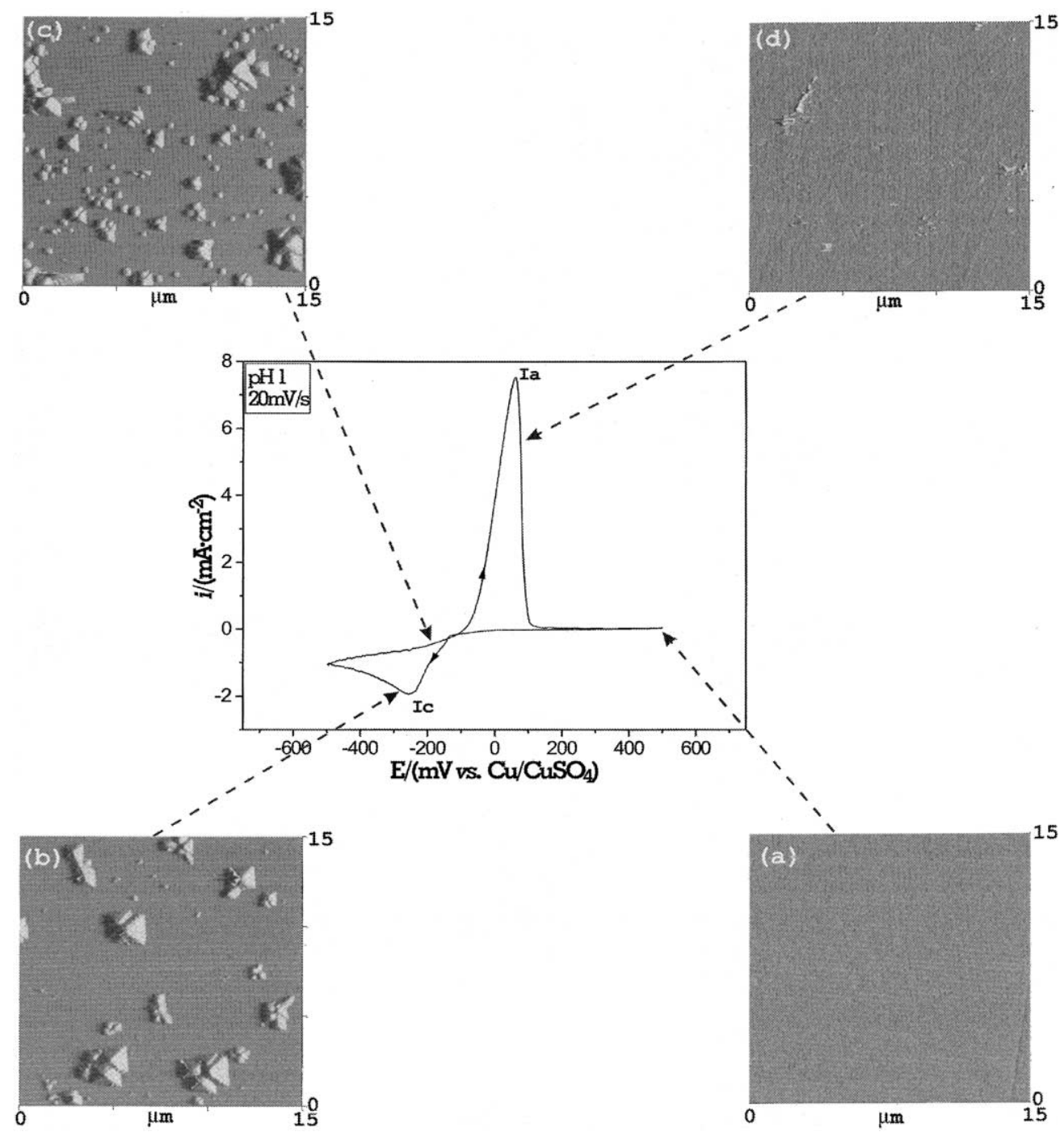

Fig. 4. (a-d) AFM of glassy carbon surface at four different stages of cyclic voltammetry.

on the glassy carbon surface as the electrode experienced more negative potentials. Going further in the positive direction, the next surface examination was performed right after the $\mathrm{cv}$ passed the peak Ia, Fig. 4d. The almost barren electrode surface clearly indicates that copper dissolution was nearly completed. The electrode surface at the end of the cv sweep had no copper present, and the surface was indistinguishable from Fig. 4a.

\subsection{Chronoamperometry for nucleation modeling}

Chronoamperometry was used as an electrochemical method for copper deposition, and simultaneously, as a technique suitable for electrochemical nucleation mechanisms studies. In chronoamperometry experiments, the potential was stepped from the open-circuit potential to the potential at which the deposition of copper would occur. Under these conditions, the system made a transition from no reaction to the steady-state reaction, controlled by the rate of mass transfer of cupric ions toward the electrode surface. Such transition is always followed by the current transient until the steady-state is achieved, as described by the Cottrell equation [11], equation (2)

$i=\frac{n F D^{1 / 2} C_{0}}{\pi^{1 / 2} t^{1 / 2}}$

where, $i$, current density; $n$, number of electrons involved; $F$, Faraday constant; $D$, diffusion coefficient; $C_{0}$, concentration of species in the bulk and $t$, time. In the case of heterogeneous systems under diffusion control, nuclei formed on the surface contribute to the active surface area available for reaction. Initial current increase for heterogeneous systems is due to the increase of surface area whenever the nucleation is involved. As nucleation progresses, the nuclei will begin overlapping. Each nucleus will define its own diffusion zone through which copper has to diffuse, representing the mass- 
supplying mechanism for continuation of growth. Since the diffusion zones are much larger than the underlying nuclei, the overlapping zones would eventually include the entire electrode area. Further reaction is strictly controlled by the rate of mass transfer through the control area of the diffusion zone, i.e. the system is under steady state conditions. Within the diffusion zone, growth of already-established copper nuclei can continue, or additional nucleation can be initiated on various sites, both governed by the steady state conditions, as described by the Cottrell equation.

Chronoamperometry is an important diagnostic electrochemical technique because it provides the current transients. These were effectively used by Scharifker and Hills [12] to derive the mathematical models that describe the nucleation mechanisms. According to the models, there are two limiting nucleation mechanisms, the instantaneous and the progressive. Instantaneous nucleation corresponds to a slow growth of nuclei on a small number of active sites, all activated at the same time. Progressive nucleation corresponds to fast growth of nuclei on many active sites, all activated during the course of electroreduction [13].

The models for instantaneous and progressive nucleation are given by equations (3) and (4), respectively [12],

$$
\begin{aligned}
& \frac{i^{2}}{i_{\mathrm{m}}^{2}}=\frac{1.9542}{\frac{t}{t_{\mathrm{m}}}}\left\{1-\exp \left[-1.2564\left(\frac{t}{t_{\mathrm{m}}}\right)\right]\right\}^{2} \\
& \frac{i^{2}}{i_{\mathrm{m}}^{2}}=\frac{1.2254}{\frac{t}{t_{\mathrm{m}}}}\left\{1-\exp \left[-2.3367\left(\frac{t}{t_{\mathrm{m}}}\right)^{2}\right]\right\}^{2}
\end{aligned}
$$

where $i_{\mathrm{m}}$ and $t_{\mathrm{m}}$ are current and time coordinates of the peak, respectively. In the following graphs, the instantaneous and the progressive mechanisms will be represented by solid and dashed lines, respectively.

\subsection{Effect of deposition potential and $p H$}

Cyclic voltammograms were consulted for selection of deposition potentials for use in ca. The potential values were selected from the more negative side of a cv peak, Ic. The effect of deposition potential on chronoamperometry was studied under three different $\mathrm{pH}$ conditions (Fig. $5 \mathrm{a}-\mathrm{c}$ ). At $\mathrm{pH} 1$, the deposition potentials were in the range -300 to $-500 \mathrm{mV}$, while at $\mathrm{pH} 2$ and 3 the deposition potentials were in the range -350 to -550 $\mathrm{mV}$. It should be noticed that the ca peaks are better defined at $\mathrm{pH} 1$ than at $\mathrm{pH} 2$ and 3. The experimental data from Fig. 5a-c were used to fit Scharifker-Hills nucleation model (Fig. 5 $\mathrm{a}^{\prime}-\mathrm{c}^{\prime}$ ). According to data in Fig. 5a', copper at $\mathrm{pH} 1$ is formed according to the instantaneous nucleation mechanism for all studied deposition potentials. However, at $\mathrm{pH} 2$ and 3 the experimental data did not follow either of the nucleation mechanisms. The possible reason could be the solution resistance under these two $\mathrm{pH}$ conditions. It should be noted that algebraic compensation for IR drop (104 and $208 \Omega$, for $\mathrm{pH} 2$ and 3 , respectively), performed by a potentiostat, could not simulate the realistic solution properties found in the presence of background electrolyte.

\subsection{Effect of copper concentration}

Effect of copper concentration on the reaction mechanisms was studied at $\mathrm{pH} 1$ for three different copper concentrations, $0.01,0.025$ and $0.05 \mathrm{M}$. Chronoamperometry experiments were performed at -450 $\mathrm{mV}$. The results are presented in Fig. 6a. The chronoamperograms were well defined with the current densities increasing with the increase of copper concentration. The corresponding fit of experimental data according to Scharifker-Hills' model is presented in Fig. 6a'. Instantaneous nucleation mechanisms were obtained for all three copper concentrations up to $t /$ $t_{\mathrm{m}}=2.0$. For extended reaction times, the calculated data in Fig. 6a' departed from the instantaneous mechanisms for higher concentrations of copper, 0.025 and $0.05 \mathrm{M}$. The exact reasons for deviation from the model are not known. According to Radisic et al. [2] the current from hydrogen reduction on formed copper nuclei can cause a deviation from the model. This explanation is questionable, however, because copper surface area from $0.01 \mathrm{M}$ copper sulfate is more readily available. The morphology of a nucleus is a more probable explanation for the deviation. Since the nucleation models are derived for hemispherical geometry, any departure from this morphology will result in deviation from the model. Thus in Fig. $9 \mathrm{~b}$ and c, it can be observed that the nuclei geometry is more dendritic/ pyramidal, and as such can serve as an explanation for the observed deviation.

\subsection{Correlation between reaction models and nuclei morphology}

The morphology of copper nuclei was examined by AFM for all studied parameters.

\subsection{1. $p H$ effect}

Copper nuclei obtained at the end of ca experiments during the $\mathrm{pH}$ effect study are presented in Fig. $7 \mathrm{a}-\mathrm{c}$. Although the nature of copper nuclei caused some difficulties during AFM (inclination of some nuclei was too steep to be resolved by a tip), several conclusions can still be drawn from the images obtained. At $\mathrm{pH} 1$, copper was deposited in the form of equally sized and somewhat rounded grains (Fig. 7a). At $\mathrm{pH}$ 2, Fig. $7 \mathrm{~b}$, the grains were no longer equally sized. Some of the 


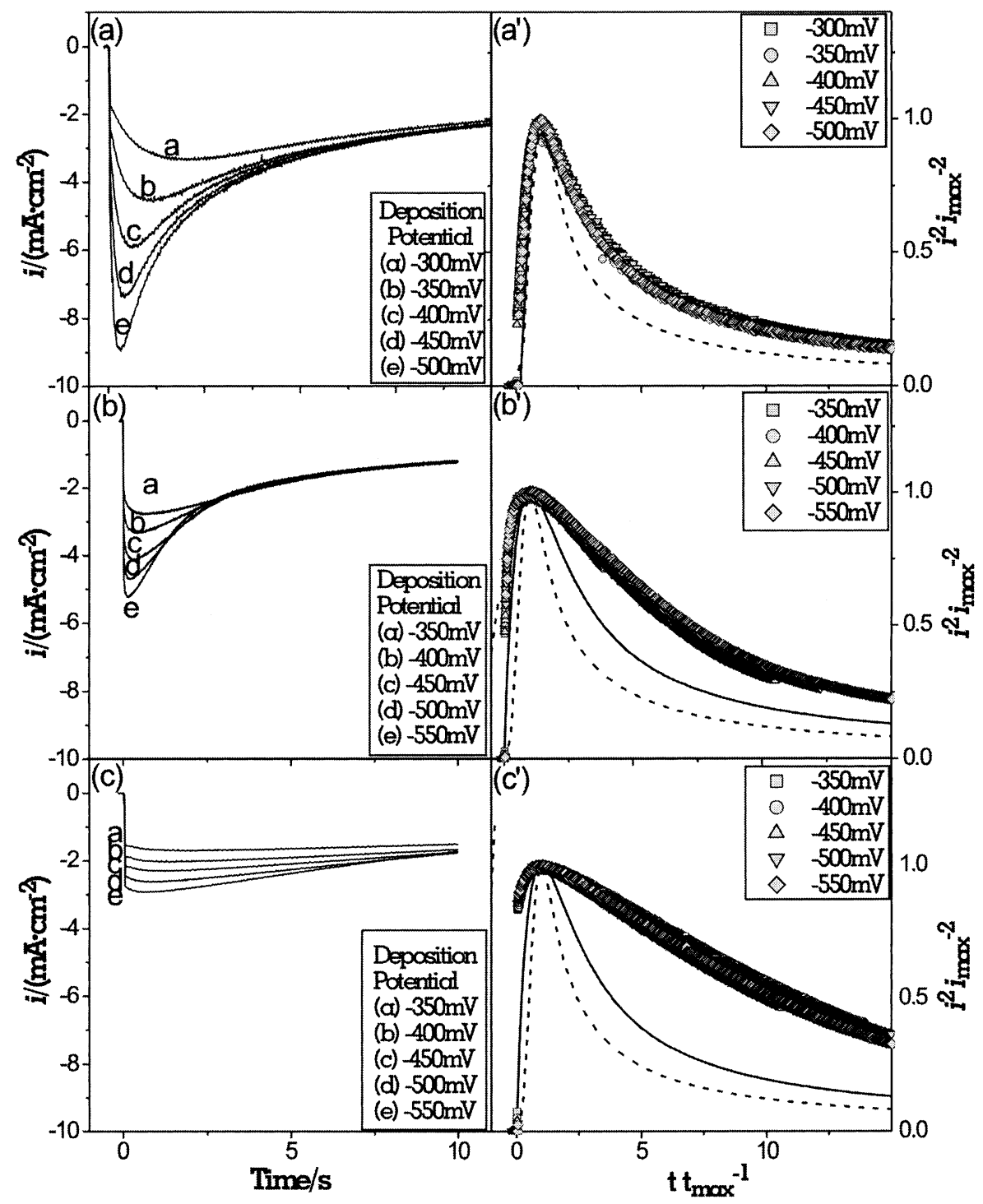

Fig. 5. (a-c) Chronoamperometry of copper during electrodeposition on glassy carbon electrode. Deposition voltage range: -300 to $-500 \mathrm{mV} ; 0.01$ $\mathrm{M} \mathrm{Cu}^{2+}$ at $\mathrm{pH} 1 ;-350$ to $-550 \mathrm{mV}$ at $\mathrm{pH} 2$ and 3. $\left(\mathrm{a}^{\prime}-\mathrm{c}^{\prime}\right)$ Corresponding Scharifker-Hills' models.

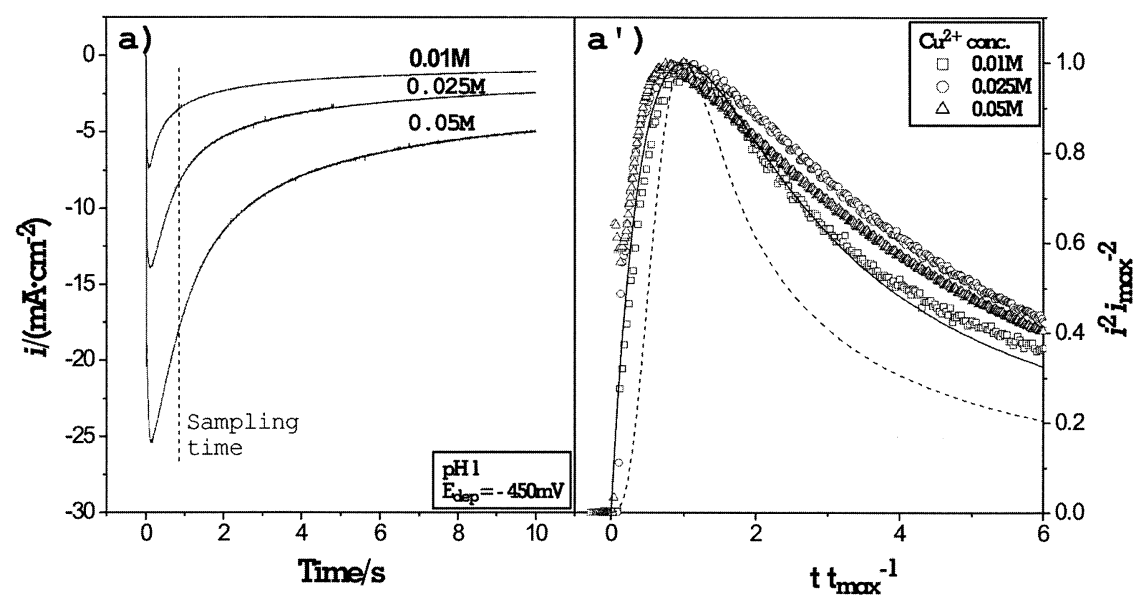

Fig. 6. (a) Effect of copper concentration on chronoamperometric deposition of copper, (a') The corresponding Scharifker-Hills' models. 

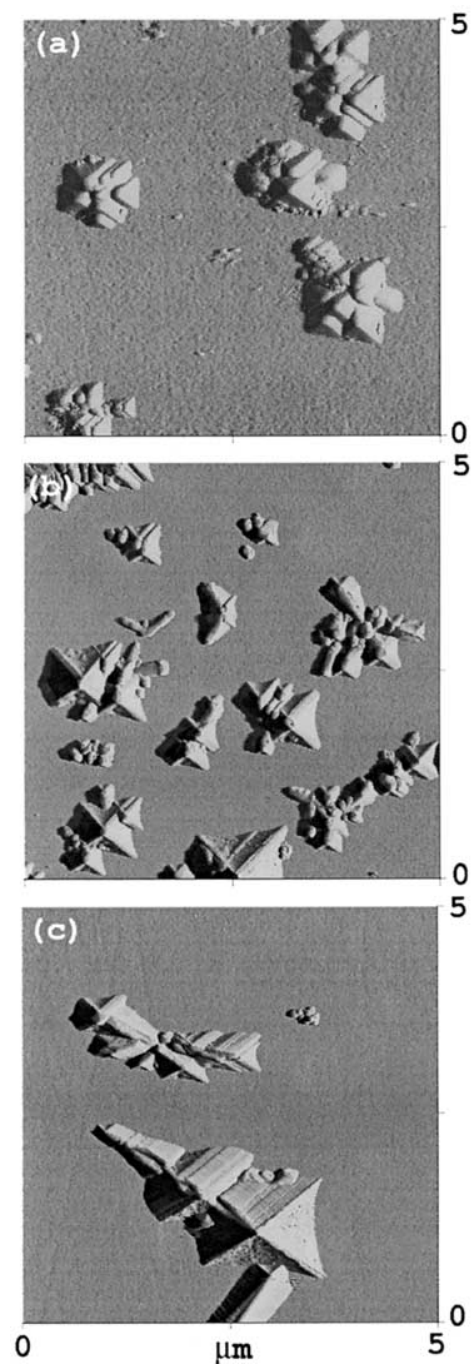

Fig. 7. AFM of electrode surface upon electrodeposition of copper at (a) $\mathrm{pH} \mathrm{1,} \mathrm{(b)} \mathrm{pH} 2$ and (c) $\mathrm{pH} 3$. Electrodeposition performed at -450 $\mathrm{mV}$ from $0.01 \mathrm{M} \mathrm{Cu}^{2+}$ solutions.

grains at $\mathrm{pH} 2(500 \mathrm{~nm})$ were quite larger than at $\mathrm{pH} 1$ $(50 \mathrm{~nm})$. At pH 3, Fig. 7c, the grains became elongated and less populated on the surface (concluded form additional images, not included here). The grain height at $\mathrm{pH} 3$ was also about $500 \mathrm{~nm}$. Thus, $\mathrm{pH}$ increase was responsible for the grain height increase, as well as the increase of irregularity of grain shapes, and the decrease of surface nuclei population density.

\subsubsection{Deposition potential}

The effect of deposition potential on morphology of copper nuclei was studied at $\mathrm{pH} 1,2$, and 3 from $0.01 \mathrm{M}$ $\mathrm{Cu}^{2+}$. Fig. 8a-c represent the results from copper deposition test at $\mathrm{pH} 1$. The ca experiments were terminated when an exact amount of copper, equivalent to $2.5 \mathrm{mC} \mathrm{cm}^{-2}$, was deposited. Each experiment was followed by the atomic force microscopic study.
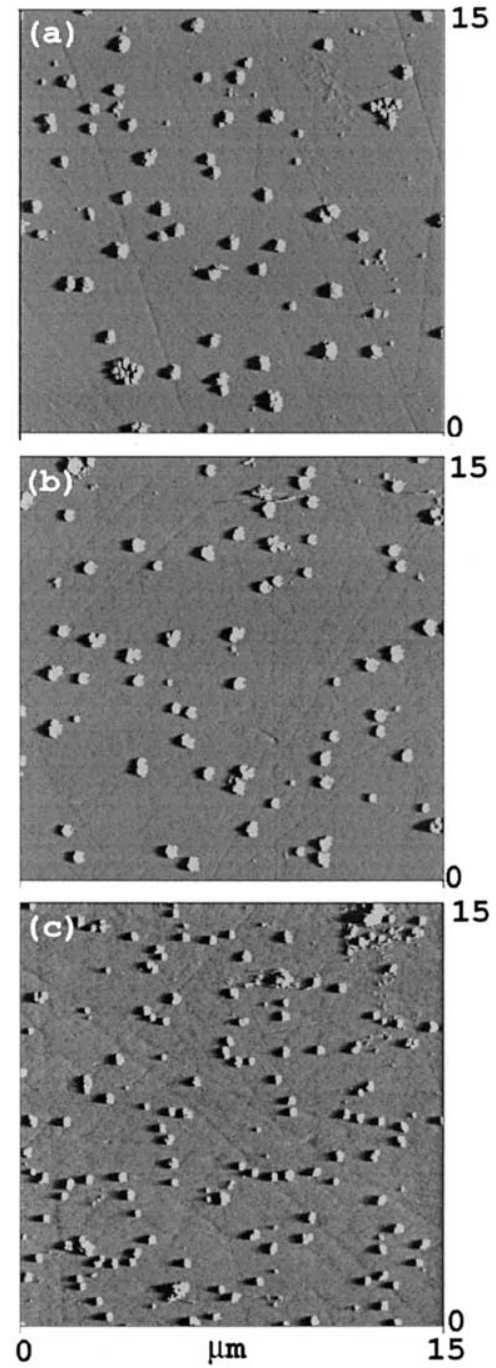

Fig. 8. Effect of deposition potential on the morphology (AFM) of deposited copper at (a) $-300 \mathrm{mV}$, (b) $-400 \mathrm{mV}$, (c) $-500 \mathrm{mV}$. Solution conditions: $0.01 \mathrm{M} \mathrm{Cu}^{2+} ; \mathrm{pH} 1$. Copper deposition equivalent to $2.5 \mathrm{mC} \mathrm{cm}^{-2}$.

It was found that deposition potential mostly affects the density of copper nuclei. At $-300 \mathrm{mV}$, Fig. $8 \mathrm{a}$, the nuclei were the largest and relatively scarce on the surface, with a measured population density of about $3.75 \times 10^{7}$ nuclei per $\mathrm{cm}^{2}$ (population density measurement was performed by Nanoscope IIIa image analysis software). An increase of deposition potential to -400 $\mathrm{mV}$, Fig. $8 \mathrm{~b}$, produced a nuclei population density of $4.19 \times 10^{7}$ nuclei per $\mathrm{cm}^{2}$. Nuclei deposited at $-500 \mathrm{mV}$, Fig. $8 \mathrm{c}$, had the highest population density at $7.32 \times 10^{7}$ nuclei per $\mathrm{cm}^{2}$. Since the amount of copper deposited was constant for each condition, the surface with the highest population density had to have the smallest nuclei, Fig. 8c. The number of active sites depends on the potential; this accounts for the increase in nuclei population density as the deposition potential increases. 


\subsubsection{Concentration effect}

The effect of copper concentration on the morphol-

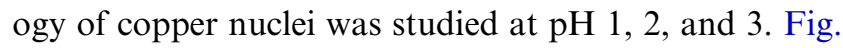
$9 \mathrm{a}-\mathrm{c}$ represents the results from the copper deposition study at $\mathrm{pH} 1$ in $0.01,0.025$ and $0.05 \mathrm{M} \mathrm{Cu}^{2+}$ solutions. The AFM images were taken $0.8 \mathrm{~s}$ after beginning each experiment for all three concentrations (Fig. 6a, line designates sampling time). For the effect of copper concentration, the ca experiments were terminated at fixed time rather than fixed amount of copper deposited, in contrast to the study of deposition potential discussed above. By fixing the time, it was ensured that the reaction was in the same stage for all three concentrations.

For the $0.01 \mathrm{M}$ copper concentration, Fig. 9a, the nuclei were relatively small and densely distributed on the surface. At a higher copper concentration, Fig. 9b,

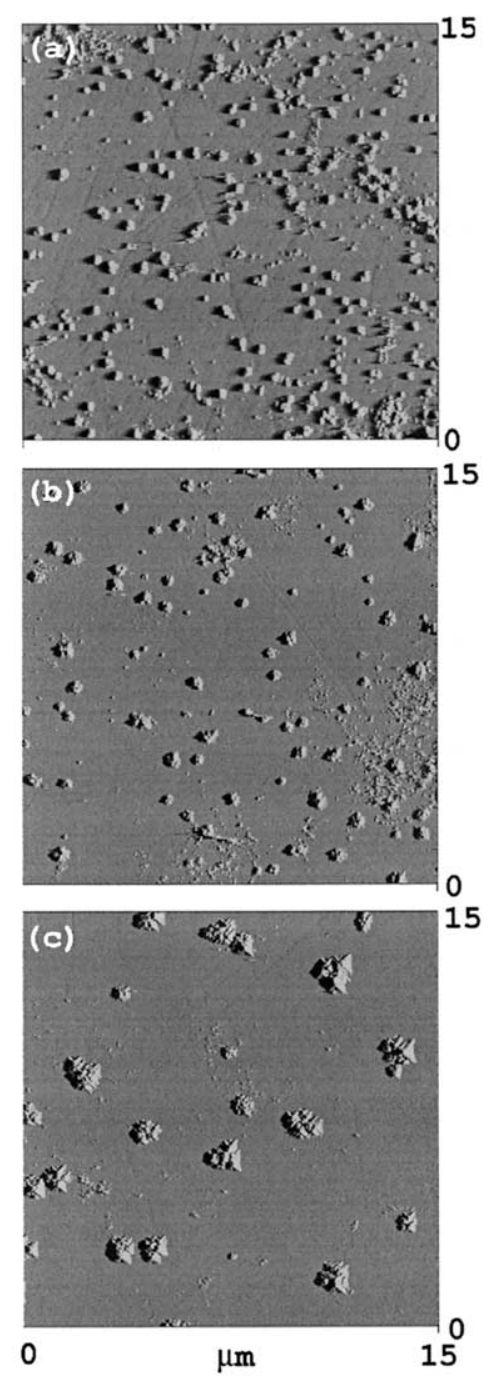

Fig. 9. Effect of concentration on the morphology (AFM) of copper deposited under potentiostatic conditions at $-450 \mathrm{mV}$ for $0.8 \mathrm{~s}$. Copper concentrations (a) $0.01 \mathrm{M}$, (b) $0.025 \mathrm{M}$, (c) $0.05 \mathrm{M}$. All solutions at $\mathrm{pH} 1$. the size of nuclei increased, but the nuclei population density decreased, which was even more pronounced at a higher copper concentration, Fig. 9c.

A schematic presentation of the effect of concentration on nuclei size distribution and governing mechanisms is given in Fig. 10a and b, for lower and higher metal concentrations, respectively. Regarding the described nucleation mechanisms, another column is added representing the stage of a chronoamperometric reaction responsible for nuclei formation, Fig. 10c. Stage I represents the initial conditions prior to the onset of the reduction reaction. A liquid boundary film layer adjacent to the solid substrate and a solution bulk are depicted. The liquid boundary film is presented in the simplest possible terms, as used by Scharifker-Hills [12], thus no double layer properties were considered. At the very beginning of electroreduction the number of copper atoms produced on the surface is a function of initial bulk concentration. In the case of lower metal concentration, Fig. 10a, the copper atoms are spaced further apart compared with the case with higher metal concentration, Fig. 10b. Once distributed over the surface in the atomic state, atoms must travel toward each other in order to minimize the surface energy. Atoms spaced further apart have to travel longer distances in order to group together and form a nucleus. Since this is energetically unfavorable they have to group together with the nearest neighbors, resulting in large number of small nuclei. On the other hand, when the initial number of reduced metal atoms is large, the close proximity of atoms will result in grouping to form a large nucleus. The size of each nucleus determines the size of its diffusion zone.

Decrease of nuclei population density with the increase of concentration was also predicted by the Scharifker-Hills model [12]. According to the model, nuclei population density can be calculated for different copper concentrations as a function of peak current $i_{\max }$ and corresponding peak time, $t_{\max }$ :

$N_{0}=0.065\left(\frac{1}{8 \pi C_{0} V_{\mathrm{m}}}\right)^{1 / 2}\left(\frac{n F C_{0}}{i_{\max } t_{\max }}\right)^{2}$

where, $n$, number of electrons involved; $F$, Faraday constant; $C_{0}$, concentration of species in the bulk; $V_{\mathrm{m}}$, molar volume; $t_{\max }$, peak time and $i_{\max }$, peak current density. Calculated and measured nuclei population densities are given in Table 1.

Data in Table 1 show that both calculated and measured nuclei densities decrease with the increase of copper concentration. The difference between the calculated and measured nuclei population densities was about one order of magnitude, contrary to the data reported by others $[2,13]$, whose difference was several orders higher. The possible explanation for the difference could be the inability of the mathematical model to 


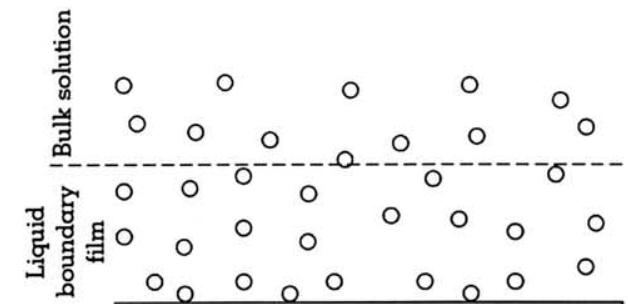

Substrate
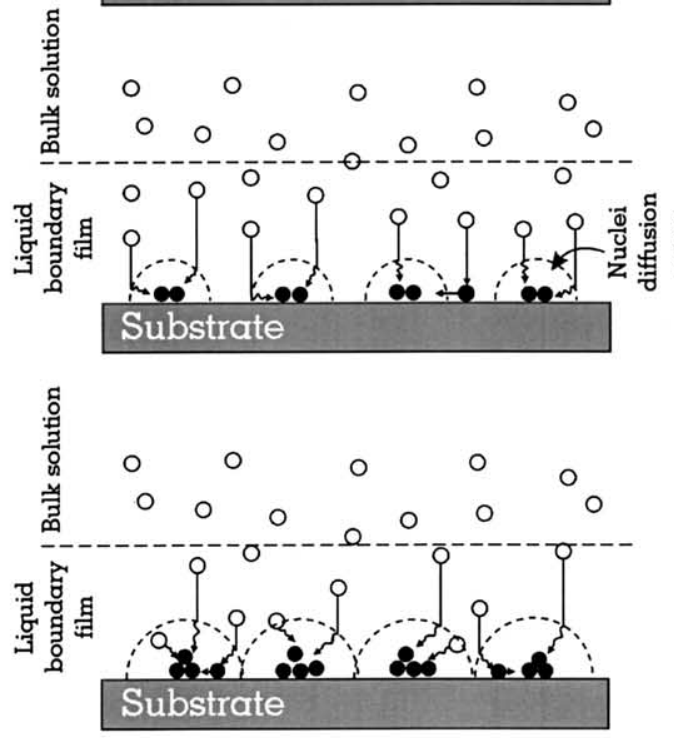

(a) Lower metal concentration

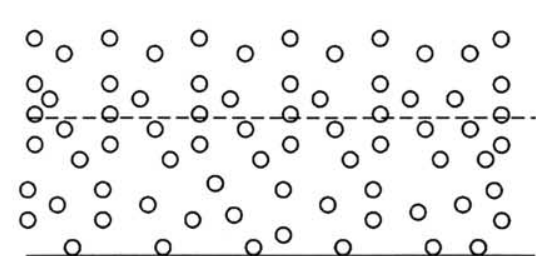

Substrate

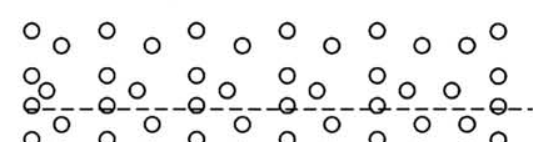

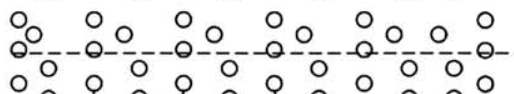

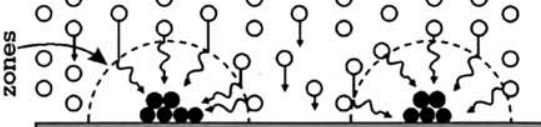

Substrate

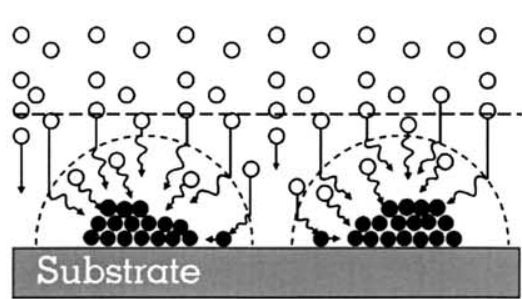

(b) Higher metal concentration

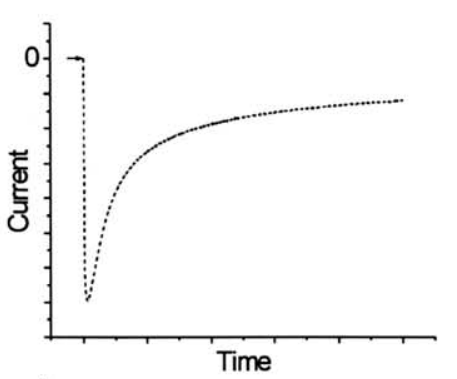

岕

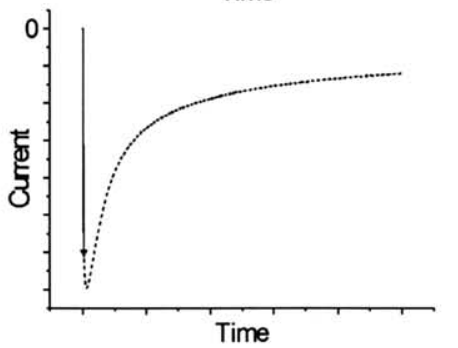

昆

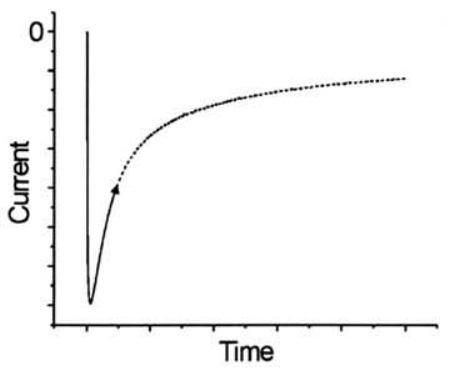

(c) Corresponding CAs

Fig. 10. Schematic presentation of phenomena involved during copper nucleation at various stages of chronoamperometric experiment for (a) lower and (b) higher concentration of metal ions. Depicted stages are (I) prior to electroreduction, (II) state at the onset of reduction and (III) steady state of electroreduction.

Table 1

Calculated and measured nuclei population densities deposited from pH 1 solutions containing $0.01,0.025$ and $0.05 \mathrm{M} \mathrm{Cu}^{2+}$ at $-450 \mathrm{mV}$

\begin{tabular}{lcc}
\hline $\mathrm{Cu}^{2+}$ concentration $\left(\mathrm{mol} \mathrm{l}^{-1}\right)$ & \multicolumn{2}{c}{ Nuclei population density $\left(\mathrm{cm}^{-2}\right)$} \\
\cline { 2 - 3 } & Calculated & Measured \\
\hline 0.010 & $11.12 \times 10^{6}$ & $92.4 \times 10^{6}$ \\
0.025 & $6.15 \times 10^{6}$ & $80.3 \times 10^{6}$ \\
0.050 & $2.09 \times 10^{6}$ & $36.1 \times 10^{6}$ \\
\hline
\end{tabular}

distinguish nucleation phenomena that could occur within the diffusion zone, e.g. more than one nuclei within a single diffusion zone [2].

\subsubsection{Samples in transient region}

One set of ca experiments was performed to study the electrode surface nucleation phenomena along the transient region. Three ca experiments were initiated $\left(\mathrm{pH} 1 ;-450 \mathrm{mV} ; 0.01 \mathrm{M} \mathrm{Cu}^{2+}\right.$ ) and then terminated after 3, 6 and $10 \mathrm{~s}$, respectively, all in the Cottrell region. Upon termination, the surface was examined by AFM, Fig. 11a-c. After 3 s, Fig. 11a, the nuclei were of similar size and randomly distributed on the surface. The average diameter was about $160 \mathrm{~nm}$, and the height about $65 \mathrm{~nm}$. After $6 \mathrm{~s}$, Fig. 11b, the nuclei size was much larger, with the average diameter of about $250 \mathrm{~nm}$, and the height $150 \mathrm{~nm}$. Among the large copper nuclei, a notable presence of smaller grains cannot be readily explained. These could be debris from tall nuclei that chipped off during scanning, deactivated original nuclei, or the initiation of additional nucleation. Unfortunately, the AFM is unable to provide a definite answer. After 10 $\mathrm{s}$, which also represents the end of a chronoamperometric experiment, Fig. 11c shows further growth of nuclei (average diameter about $370 \mathrm{~nm}$, height $190 \mathrm{~nm}$ ).

\subsection{Effect of background electrolyte}

As previously mentioned, in order to overcome the problem with uncompensated solution resistance, sodium sulfate was introduced as a background electrolyte. According to Fig. $5 \mathrm{a}^{\prime}-\mathrm{c}^{\prime}$, the $\mathrm{pH}$ had an important effect on copper nucleation mechanisms in the solutions without background electrolyte. Furthermore, at $\mathrm{pH} 2$ 

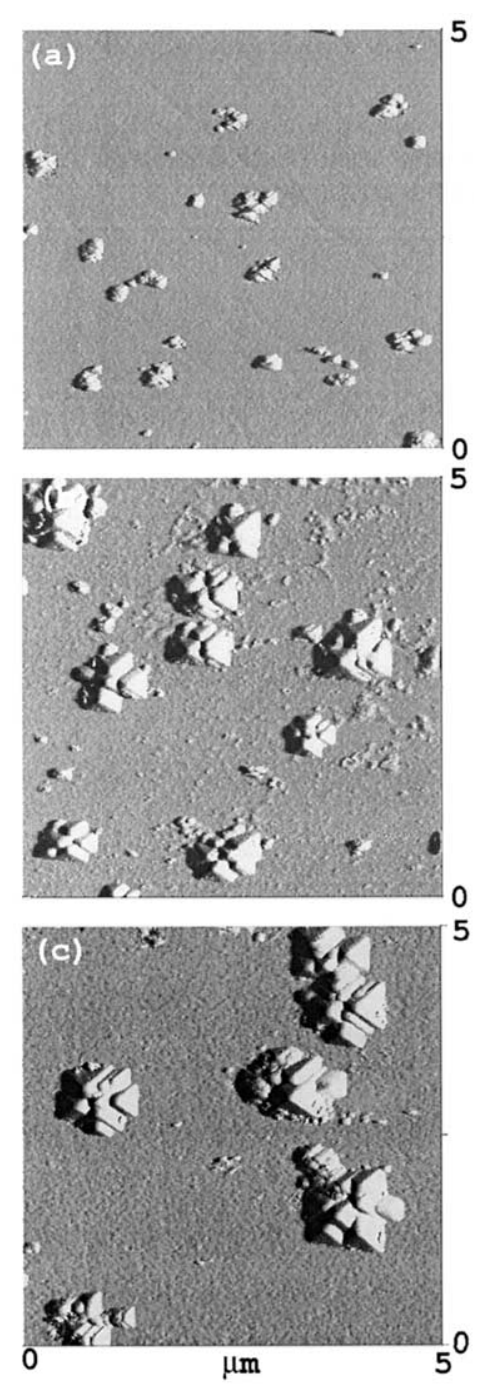

Fig. 11. Copper nuclei morphology along the transient pathway after (a) $3 \mathrm{~s}$, (b) $6 \mathrm{~s}$ and (c) $10 \mathrm{~s} ; 0.01 \mathrm{M} \mathrm{Cu}^{2+}, \mathrm{pH} 1$.

and 3, copper nucleation mechanisms did not fit the nucleation model of Scharifker-Hills.

The role of background electrolyte was studied by repeating the effect of $\mathrm{pH}$ experiments in the presence of 1.0 M sodium sulfate solutions. The results are presented in Fig. 12a-a'.

At $\mathrm{pH} 3$ copper nucleation followed the progressive nucleation model during the entire reaction time, Fig. 12a' (triangle symbols). At pH 1 and 2, however, copper initiated the nucleation on the surface according to the progressive nucleation mechanisms, but with time, the mechanism shifted toward the instantaneous mode (closed circle and square symbols approach the solid, instantaneous model, line). The departure from progressive nucleation mechanism was at about $t / t_{\max }=2$.

Fig. 13a-c provide further proof of the difference in nucleation mechanisms as a function of $\mathrm{pH}$. The size of nuclei deposited at $\mathrm{pH} 1$ and 2, Fig. 13a-b, corresponding to the end of $t / t_{\max }$ scale, was almost uniform, characterizing the instantaneous nucleation. However, at the $\mathrm{pH} \mathrm{3,} \mathrm{Fig.} \mathrm{13c,} \mathrm{the} \mathrm{size} \mathrm{of} \mathrm{nuclei} \mathrm{deposited} \mathrm{was}$ fairly random, a characteristic for progressive nucleation.

The effect of background electrolyte results, Fig. 12a$\mathrm{a}^{\prime}$ and Fig. 13a-c, are very intriguing and deserve a separate study. No further attention was given to this parameter in this paper.

\subsection{Diffusion coefficients calculation}

Since the Cottrell equation (2) describes the system under a diffusion-controlled regime, the expression can be utilized for calculating diffusion coefficients. The plot of current density versus inverse square root of time should be linear and pass through the origin. The slope of the line contains the information on the diffusion coefficient. According to Fig. 14, the effect of $\mathrm{pH}$ in the absence of a supporting electrolyte, a straight line relationship was obtained only for $\mathrm{pH} 1$ (open square symbols). In the presence of $1.0 \mathrm{M}$ sodium sulfate, as described previously, $\mathrm{pH}$ had no effect; thus all $\mathrm{pH}$ data fell close to one straight line (closed symbols). The diffusion coefficient calculated in the absence of background electrolyte was $0.8 \times 10^{-5} \mathrm{~cm}^{2} \mathrm{~s}^{-1}$, compared with the values of $0.57-0.61 \times 10^{-5}$ published elsewhere $[3,14,15]$, while in the presence of background electrolyte, the diffusion coefficient was $0.43 \times 10^{-5}$.

\section{Conclusions}

The electrochemistry combined with the AFM was a successful experimental approach for studying the copper nucleation mechanisms during electrodeposition. The electrochemical techniques had a dual role: (a) copper electrodeposition, and (b) mechanistic interpretation. The AFM microscopy was a useful tool for correlating the size distribution of copper nuclei with the electrochemical findings.

Among the studied parameters, it was determined that copper concentration, deposition potential, solution $\mathrm{pH}$ and the presence of a background electrolyte all had profound effects on the nucleation mechanisms of copper on the glassy carbon surface. An increase of $\mathrm{pH}$ and copper concentration produced nuclei with a coarser texture and lower population density. An increase of deposition potential and addition of background electrolyte had opposite effects. In the absence of background electrolyte, the nucleation models of Scharifker and Hills [12], additionally supported by morphological information produced by AFM, showed that copper nucleates according to instantaneous mechanisms at $\mathrm{pH} 1$. At $\mathrm{pH} 2$ and 3, the mechanism was inconclusive. In the presence of background electrolyte, at $\mathrm{pH} 1$ and 2 the mechanism of nucleation shifted from 


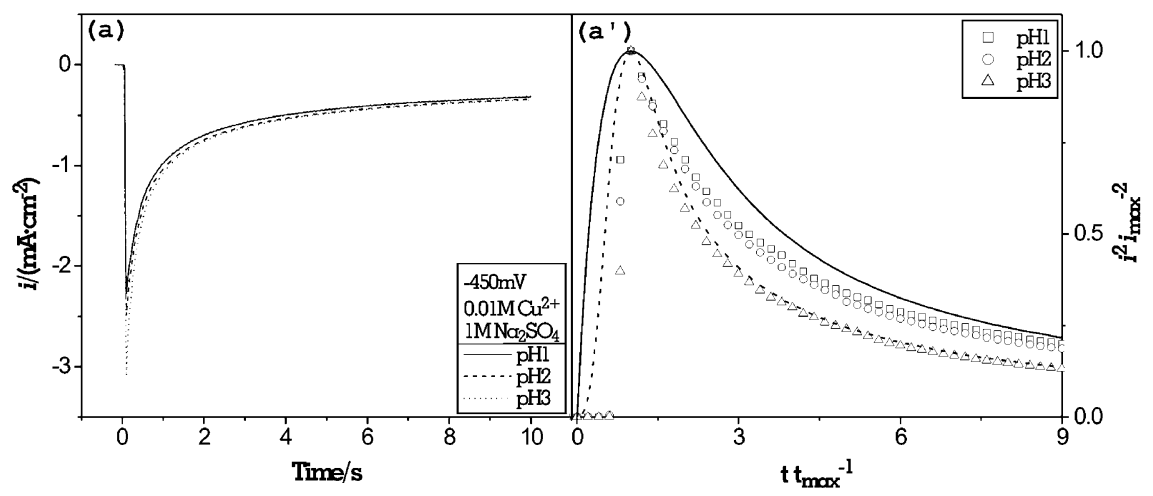

Fig. 12. ( $\left.\mathrm{a}-\mathrm{a}^{\prime}\right)$ Actual current transients (symbols) at $\mathrm{pH} 1,2$ and 3 for solutions containing $1 \mathrm{M}$ of sodium sulfate and $0.01 \mathrm{M} \mathrm{Cu}^{2+}$ in comparison to the theoretical models (lines). Deposition potential at $-450 \mathrm{mV}$.
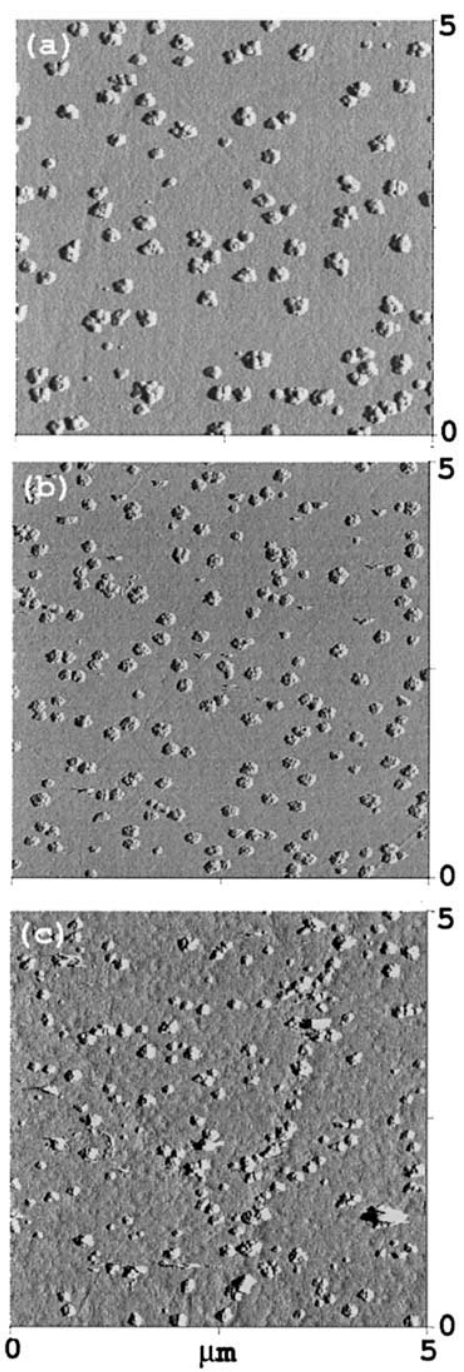

Fig. 13. Effect of $\mathrm{pH}$ on morphology of copper nuclei in the presence of $1.0 \mathrm{M} \mathrm{Na}_{2} \mathrm{SO}_{4}$ background electrolyte; (a) $\mathrm{pH} \mathrm{1,} \mathrm{(b)} \mathrm{pH} 2$, (c) $\mathrm{pH} 3$; deposition potential $-450 \mathrm{mV} ; 0.01 \mathrm{M} \mathrm{Cu}^{2+}$.

progressive to instantaneous during electrodeposition. At $\mathrm{pH} 3$, the mechanism was purely progressive.

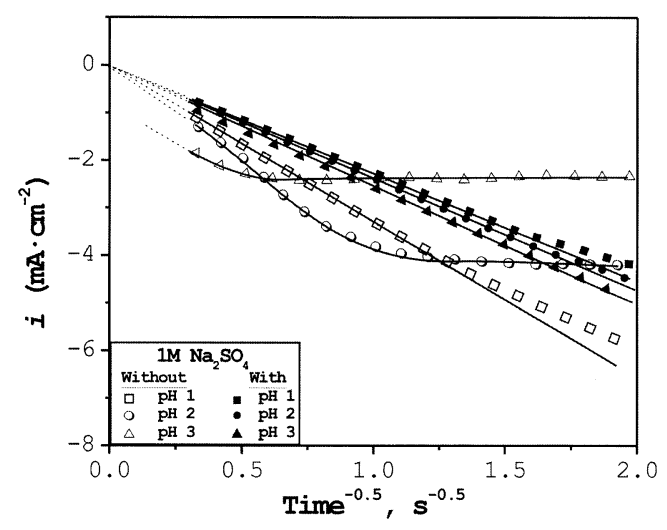

Fig. 14. ( $\left.a-a^{\prime}\right)$ Cottrell plots as a function of $\mathrm{pH}$ with (closed symbols) and without (open symbols) background electrolyte. Data from related chronoamperometry at $-450 \mathrm{mV}$ deposition potential and $0.01 \mathrm{M}$ $\mathrm{Cu}^{2+}$.

\section{Acknowledgements}

This work has been sponsored by the US Department of Defense, Department of the Navy, Office of Naval Research, Grant Number N000140110829.

\section{References}

[1] M. Schlesinger, M. Paunovic, Modern Electroplating, fourth ed., Wiley, New York, NY, 2000.

[2] A. Radisic, J.G. Long, P.M. Hoffmann, P.C. Searson, J. Electrochem. Soc. 148 (1) (2001) C41.

[3] G. Oskam, P.M. Vereecken, P.C. Searson, J. Electrochem. Soc. 146 (4) (1999) 1436.

[4] A. Ramos, M.M. Hernandez, I. Gonzales, J. Electrochem. Soc. 148 (4) (2001) C315.

[5] C. Nila, I. Gonzales, J. Electroanal. Chem. 401 (1996) 171.

[6] D. Grujicic, B. Pesic, in preparation.

[7] J.L. Alvarez, J.A.G. Calzon, J.M.L. Fonseca, Electrochim. Acta 45 (1999) 477.

[8] A. Bettelheim, A. Raveh, U. Mor, R. Idgar, B. Segal, J. Electrochem. Soc. 137 (10) (1990) 3151.

[9] D. Grujicic, B. Pesic, in preparation. 
[10] H.-H. Huang, StABCAL-Stability Calculation for Aqueous Systems, Montana Tech, The University of Montana, Butte, MT, 2002.

[11] Southampton Electrochemistry Group, in: T.J. Kemp (Ed.), Instrumental Methods in Electrochemistry, Ellis Horwood Ltd, Chichester, UK, 1985.
[12] B. Scharifker, G. Hills, Electrochim. Acta 28 (7) (1983) 879.

[13] M.P. Pardave, M.T. Ramirez, I. Gonzales, A. Serruya, B.R. Scharifker, J. Electrochem. Soc. 143 (5) (1996) 1551.

[14] E. Gileadi, V. Tsionsky, J. Electrochem. Soc 147 (2) (2000) 567.

[15] M. Georgiadou, D. Vegret, R.L. Sani, R.C. Alkine, J. Electrochem. Soc. 148 (1) (2001) C54. 